\title{
A Tough Nut to Crack: A Semantico-Syntactic Analysis of TOUGH-Constructions in Contemporary English
}

\begin{abstract}
$\underline{\text { Abstract }}$
It seems appropriate to call "tough constructions" or "hard nuts" structures such as John is easy to please: they are indeed very difficult to analyse in the framework of the theory of Government and Binding, particularly if one wants to take into account all their semantic and syntactic properties. The majority of previous studies only deal with one aspect (semantic or syntactic) of the problem, and in some cases, the derivation itself is problematic because it violates principles inherent to the theory used (Rosenbaum 1967 and Postal 1971, Chomsky 1981).

Through the study of a significant corpus of authentic examples, this article attempts to provide a viable syntactic analysis of "tough" constructions that takes into account their semantic properties. The requirement for some kind of evaluation from the speaker is explained by the presence, in the structure, of the semantic projection "Evaluation Phrase". We couple Chomsky (1981)'s complex adjective with the chain theory in order to solve the problem posed by the presence of a patient in subject position: the formation of this unit cuts the chain between the raised internal argument and the trace its movement leaves. This inactivates the accusative case the argument gets in object position, allowing it to get nominative case from the upper inflexion.

This analysis has the advantage of providing a solution to several problems posed by "tough" constructions: the evaluative meaning, the presence of a patient in subject position and also the optionality of the infinitival subordinate clause.
\end{abstract}

\section{Résumé}

Les noms "tough constructions" ou "hard nuts" semblent appropriés pour faire référence à des structures telles que John is easy to please : elles sont en effet très difficiles à analyser dans le cadre de la théorie du Gouvernement et du Liage, tout particulièrement si l'on tente d'expliquer toutes leurs propriétés sémantiques et syntaxiques. Dans la plupart des études précédentes, seul un aspect (sémantique ou syntaxique) du problème est traité et dans certains cas, la dérivation ne fonctionne pas parce qu'elle viole certains principes inhérents à la théorie utilisée (Rosenbaum 1967 et Postal 1971, Chomsky 1981). 
A travers l'étude d'un corpus d'exemples authentiques, cet article propose une analyse syntaxique viable des constructions "tough", qui prend en compte leurs propriétés sémantiques. La présence obligatoire d'une certaine forme d'évaluation par le locuteur est expliquée par l'utilisation de la projection syntaxique "Evaluation Phrase". Nous associons l'adjectif complexe de Chomsky (1981) à la théorie des chaînes afin de résoudre le problème que pose la présence d'un patient en position sujet : la formation de l'unité adjectivale coupe la chaine entre l'argument déplacé et la trace qu'il laisse derrière lui. Ceci inactive le cas accusatif que l'argument obtient en position d'objet et lui permet ainsi d'être marqué au nominatif par l'inflexion.

Cette analyse présente l'avantage de fournir une explication à plusieurs des problèmes posés par les constructions "tough" : l'interprétation évaluative, la présence d'un patient en position de sujet, mais aussi le caractère optionnel de la proposition subordonnée infinitive. 
TOUGH-constructions have often been studied from a syntactic point of view. However, most analyses only take into account the case problem their derivation poses, and rarely the different semantic restrictions that are imposed on them. These semantic properties cannot be overlooked since they are central to the understanding of the mechanisms involved in the production of TOUGH-constructions.

The analysis we present here is based on the study of a corpus of attested examples taken from books, online websites, films, articles, conversations, etc.

The compilation of our corpus has enabled us to differentiate several structures that could be called TOUGHconstructions or which seem to function like them. Examples (1) and (2) illustrate what is most commonly considered as TOUGH-constructions:

(1) The mobile explosion is extraordinary to behold

http://www.tdctrade.com/imn/01082304/electronic03.htm

(2) They will be difficult to convince

Marion Zimmer Bradley, The Shadow Matrix, DAW Books, 1997, p. 493.

In a variant of the TOUGH-construction, the adjective modifies the head noun inside a noun phrase:

(3) You're one tough nut to crack

Maria V. Snyder, Spy Glass, Mira Books, 2010, p. 118

(4) Battles were dangerous places to be

Trudi Canavan, Voice of the Gods, Orbit, 2007, p. 517

In some examples, there is no adjective and the modification is introduced by a quantifier:

(5) It'll be too much for my ego to stand

Maria V. Snyder, Poison Study, MIRA Books, 2005, p. 224

(6) I know this is a lot to process

Private Practice, 'In Which Charlotte Goes Down the Rabbit Hole', 106, David Solomon, 2007

In the following examples, there is no adjective or quantifier but only a noun phrase (determiner + noun):

(7) That damned magazine of yours is a bitch to find

BNC HGN

(8) She is a delight to behold

www.ebay.com add - http://cgi.ebay.com.au/_W0QQitemZ5666586705QQ

Last, one rarely studied variant can contain the sequences "cost $\mathrm{X}$ to V" or "take NP to V":

(9) This is costing me $\$ 2.40$ to send

Bill Watterson, Calvin and Hobbes, The Indispensable Calvin and Hobbes, A Calvin and Hobbes Treasury, Andrews McMeel Publishing, 1992, p. 168

(10) The trip took nearly four years to complete

Freakylinks, 'Subject : Fearsum', 1AEF79, Todd Holland, 2000

In this paper, we will concentrate on "classical" TOUGH-constructions such as in examples (1) and (2), leaving the other variants for future study. 
We will begin with a basic description of TOUGH-constructions and a quick presentation of two previous syntactic analyses: the raising analysis proposed by Rosenbaum (1967) and Postal (1971), and the complex adjective analysis, suggested by Chomsky (1981). We will show why they cannot be used in the framework used in this article, i.e. the theory of Government and Binding.

We will then describe TOUGH-constructions from a semantic point of view, concentrating on the requirement that the sentence contain some element adding the evaluation of the speaker. We will show that in most cases, it is the adjective that provides the evaluative interpretation. But in other cases, an adverb or a negation can play this role.

In a third part, we will show that TOUGH-constructions do not all behave the same way syntactically. This will enable us to distinguish two kinds of TOUGH-constructions: easy TOUGH-constructions and pretty TOUGH-constructions.

Finally, we will present our syntactic analysis, taking into account the different semantic and syntactic properties described in the previous sections of this paper. Mostly, we will provide an explanation to the apparent case problem raised by Rosenbaum's (1967) and Postal's (1971) analysis, that is the two cases borne by the internal argument.

\section{Basic description of TOUGH-constructions and earlier syntactic analyses}

The TOUGH-constructions we are going to study here are composed of two clauses:

$>$ a main clause, containing:

- a nominal (11) or clausal (12) subject marked with the nominative case ${ }^{1}$ (12)-(13) and theme role

- a state verb

- an adjective, possibly modified by an adverb (14) and selecting a clausal complement.

> an infinitive clause, constituting the clausal argument of the adjective and containing a direct or indirect (15) transitive verb. The subject of this verb may or may not be realised (16), but its grammatical object can never be overt (17) unless the subject is an expletive pronoun (18).

(11) ProTeXt is easy to install

Nicola L. C. Talbot, 'LaTeX for complete novices' -

http://theoval.cmp.uea.ac.uk/ nlct/latex/novices/novices_a4.pdf

(12) What Leonie had done had been difficult to endure

Marion Zimmer Bradley, The Forbidden Tower, DAW Books, 1977, p. 363

(13) *Them are hard to destroy

(14) It's too complicated to explain

K.J. Parker, Pattern, Orbit, 2003, p. 229

(15) Some things were too hard to think about

Terry Pratchett, Men at Arms, Corgi, 2003, p. 365

\footnotetext{
${ }^{1}$ In this article, we will not go into the question of whether clausal arguments get case.
} 
(16) This is hard (for you) to hear

Buffy the Vampire Slayer, 'Selfless', 7ABB05, David Solomon, 2002

(17) *This is hard for you to hear this

(18) It is hard for you to hear this

The subject of the main clause is interpreted as co-referent to the missing internal argument. That is why Rosenbaum (1967) and Postal (1971) claim that TOUGH-constructions involve the raising of the internal argument to the position of subject of the main clause:

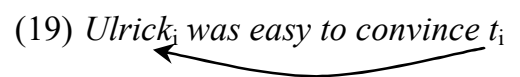

This analysis, however, is not tenable in the Government and Binding Theory as it is today. The problem is that if the subject NP indeed raised as shown in (19), it would bear two cases: accusative case (which it would have received in object position) and nominative case (assigned to all subjects). However, this situation is forbidden by the Case Filter: arguments can have one and only one case.

Chomsky (1981) provides a solution to this problem. According to him, the derivation of TOUGHconstructions involves the creation of a complex adjective composed of the adjective and its clausal complement:

(20) Ulrick was easy to convince

Maria V. Snyder, Storm Glass, Mira Novel, 2009, p. 436.

a) The PRO operator is first inserted in the object position of the infinitival verb, from which it gets a semantic role:

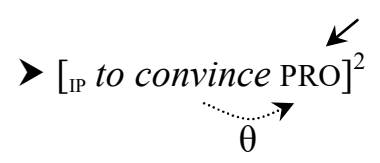

b) PRO rises to $[\mathrm{Spe}-\mathrm{CP}]^{3}$, leaving a trace $\mathrm{t}$ behind:

$$
>\left[{ }_{\mathrm{CP}} \mathrm{PRO}_{\mathrm{i}}\left[\mathrm{IP} \text { to convince } \mathrm{t}_{\mathrm{i}}\right]\right]
$$

c) The adjective is inserted and merges with its clausal complement:

$$
>\left[{ }_{\mathrm{AP}} \text { easy }\left[{ }_{\mathrm{CP}} \mathrm{PRO}_{\mathrm{i}}\left[{ }_{\mathrm{IP}} \text { to convince } \mathrm{t}_{\mathrm{i}}\right]\right]\right]
$$

At this point, a structural re-analysis occurs and "unifies" part of the structure of the adjectival phrase. It creates the lexical element easy to convince which has no internal structure:

$$
\left.\left.>{ }_{\mathrm{AP}}\left[{ }_{\mathrm{A}} \text { easy to convince }\right] \mathrm{t}_{\mathrm{i}}\right]\right]
$$

The syntactic subject is then inserted directly in [Spe-IP]. It gets a case from the main clause and the role that is transmitted by the trace $\mathrm{t}_{\mathrm{i}}$ via the chain they form:

$$
\left.>{ }_{\mathrm{IP}} \text { Ulrick } \mathrm{i}_{\mathrm{i}} \text { is }\left[_{\mathrm{AP}}\left[{ }_{\mathrm{A}} \text { easy to convince }\right] \mathrm{t}_{\mathrm{i}}\right]\right]
$$

\footnotetext{
${ }^{2}$ This structure also contains $\mathrm{PRO}_{\mathrm{arb}}$, which is the non-realised arbitrary subject of the infinitival clause.

${ }^{3}$ Chomsky 1981 compares TOUGH-constructions with WH-clauses and suggests that TOUGH derivation is similar to WH-movement.
} 


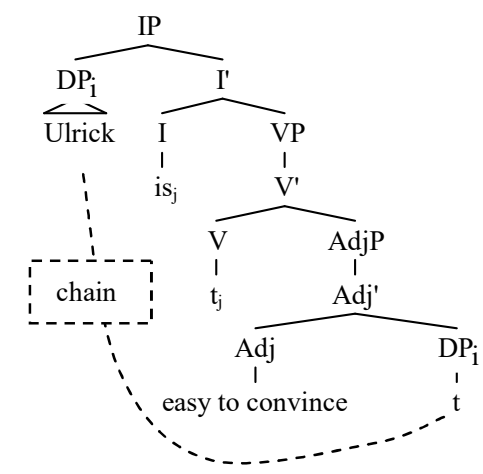

The problem with this analysis is that Chomsky positions PRO, which he says to be null and silent because it does not get case, in a case position: the object of the infinitival verb. Therefore, such an analysis cannot work in the framework of the theory of Government and Binding, which Chomsky uses.

One solution within this theory would be to use pro instead of PRO: pro is indeed a personal pronoun (albeit without phonetic realisation) and therefore can be case-marked.

\section{$\underline{\text { 2. Semantic properties of TOUGH-constructions }}$}

TOUGH-constructions express a property that, according to the speaker, is assigned to the grammatical subject: it is easy to convince, or hard to hear. Therefore, there needs to be some kind of evaluation. This is expressed by the adjective which, in most cases, is evaluative:

(21) Kenneth Branagh is great to work with

http://www.smashboxstudios.com/yello/?p=858

(22) We are hard to kill.

Marion Zimmer Bradley, To Save a World, 'The World Wreckers', DAW Books, 2004, p. 380

However, not all TOUGH-constructions contain an evaluative adjective. They can also be purely descriptive:

(23) The piece of curved pottery had been too broken for anyone to loot

Terry Pratchett, Small Gods, Corgi, 1993, p. 279

(24) The skin was flexible enough to draw across the frame

Anne McCaffrey, Dragonsinger : Harper of Pern, Corgi, 1978, p. 114.

(25) That area is too spread out to defend

Elizabeth Haydon, The Assassin King, Tor Fantasy, 2007, p. 275

(26) The religious scenes on the wall were too coated in dust to make out

Trudi Canavan, Voice of the Gods, Orbit, 2007, p. 368

Among the 139 adjectives of our corpus, 110 (79,85\%) are evaluative and $16(11,51 \%)$ are purely descriptive. The 13 remaining adjectives have not behaved consistently with regards to the tests used: we have browsed the Internet for examples of the sequences « GN find GN Adj» and «arguably Adj». We classified as evaluative any adjective that could be used in these sequences. The 13 adjectives that could not be sorted into one of the two categories (evaluative or descriptive) could be found in only one of the sequences. This might suggest two things: either our tests are not satisfactory and they must be changed, or there is some kind of "evaluativeness" cline along which adjectives are positioned. We do not believe that 
our tests are entirely satisfactory since, as we are going to see below, they sort adjectives that seem to us to be evaluative into the descriptive category. However, despite the problems inherent to these tests, it is obvious that the number of evaluative adjectives is far higher to the number of descriptive adjectives.

Moreover, whichever kind of adjective is used, the notion of evaluation is still present: descriptive adjectives are (almost) always modified by an adverb:

(27) The outer walls are too sheer to climb

Maria V. Snyder, Power Study - http://www.mariavsnyder.com/powerstudy.php

(28) * The outer walls are sheer to climb

(29) The skin was flexible enough to draw across the frame

(30) *The skin was flexible to draw across the frame

Here, the adverbs too and enough add the evaluation the descriptive adjective cannot provide. Other adverbial modifications are possible. In our corpus, we have examples of comparative (31) and superlative (32) structures, and also negations, either lexical (barely, never) (33) or grammatical (not) (34):

(31) It's [a glass studio made out of wood] cheaper and faster to build

Maria V. Snyder, Storm Glass, Mira Novel, 2009, p. 204.

(32) Which martial art is the fastest to learn

http://www.uncrate.com/answers/which-martial-art-is-the-fastest-to-learn-for-self-defense-in-real-lifesituations/index.php

(33) Most women considered the stuff barely fit to eat

Marion Zimmer Bradley, Thendara House, DAW Books, 1983, p. 159

(34) The answer was not far to seek

Marion Zimmer Bradley, Heritage and Exile, 'Sharra's Exile', Fantasy Daw, 1975, p. 525

In our corpus, five of the adjectives that the tests sort into the descriptive group appear in examples in which there is no adverb:

(35) More information about this tool: fast to download and run

http://support.intel.com/support/graphics/detect.htm

(36) [the hammer] was fit to use

K.J. Parker, Pattern, Orbit, 2003, p. 550

(37) Needless to say...

K.J. Parker, Memory, Orbit, 2003, p. 475

(38) ... rain that was gray to see through

John Steinbeck, The Grapes of Wrath, Text and Criticism (Viking Critical Library), Penguin, 1992, p. 432.

(39) The concept of contract is big to explain

http://webdesign.ittoolbox.com/groups/technical-functional/oop-1/abstract-methods-552582

We believe that apart from gray, these adjectives are in fact evaluative. Fast, big and fit are subjective terms and therefore are left to the appreciation of the speaker. Moreover, only a minority of the examples featuring these adjectives do not contain an adverbial modification: only one out of our 6 examples of fast, 4 out of the 9 examples of the adjective fit and 1 out of the 14 examples of big. 
None of our examples of needless contain an "external" adverbial modification. This is not due to the ungrammaticality of this adjective with degree adverbs, since needless is gradable:

(40) That was a cruel and very needless comment.

http://www.dailyecho.co.uk/news/4870092.Mass_brawl_at_city_tower_block/

(41) I CANNOT forego the pleasure of dedicating this little book to you; excepting of course the opening exhortation (needless enough in your case) to those who have not yet discovered the value of Natural History.

Charles Kingsley, Glaucus, or The Wonders Of The Shore

http://www.wordiq.com/books/Glaucus,_or_The_Wonders_Of_The_Shore/

Less is a privative suffix and therefore it expresses in itself some kind of the adverbial modification required: the negation. Moreover, less is affixed to the stem need which, being modal, implies a judgment from the speaker and therefore an evaluation. Since the adjective needless is formed by combining two elements that are in themselves evaluative, there is no reason why it should not be evaluative as well.

We have only one example of the adjective gray and there is no adverbial modification, as can be seen in (38). We have been unable to find any other example of TOUGH-constructions with this adjective ${ }^{4}$ without any kind evaluation. Considering these data, we believe that only gray can be sorted into the descriptive category.

Nevertheless, we can note that what is gray here is not the rain itself but the light, as can be seen in the last clause of the extended context of example (38):

\footnotetext{
The rain began with gusty showers, pauses and downpours ; and then gradually it settled to a single tempo, small drops and a steady beat, rain that was gray to see through, rain that cut midday light to evening.
}

As pointed out by an anonymous reviewer, the heavy density of the downpour makes it appear gray and the speaker evaluates the rain as an obstacle to visual perception.

\section{$\underline{\text { 3. Syntactic properties of TOUGH-constructions }}$}

TOUGH-constructions can be separated into two groups if we consider their surface syntactic behaviour. Indeed, what we will call pretty TOUGH-constructions and easy TOUGH-constructions do not behave the same way regarding the use of the expletive pronoun it and the deletion of the infinitival complement of the adjective: easy TOUGH-constructions accept the use of the expletive but not the deletion of the infinitival complement, while pretty TOUGH-constructions do not have an "expletive variant" but do accept, under certain conditions as we will show, the deletion of the infinitival complement.

It is possible to differentiate between constructions that accept a variant in "it" (easy TOUGHconstructions) and those that do not (pretty TOUGH-constructions):

(42) Dinosaurs were easy to get along with

Fantasia, Samuel Armstrong, James Algar, Bill Roberts, 1940

\footnotetext{
${ }^{4}$ Or another colour adjective.
} 
(43) It was easy to get along with dinosaurs

(44) Trolls ain't pretty to look at

Terry Pratchett, Lords and Ladies, Corgi, 2001, p. 136

(45) *It ain't pretty to look at trolls

The grammatical subject of (42), dinosaurs, is in the object position of the infinitival verb in (43), while the subject position of the copula is filled by the expletive it in order to satisfy Chomsky's (1981) Extended Projection Principle, which states that every sentence needs a subject ${ }^{5}$. As (45) shows, there can be no expletive variant with pretty TOUGH-constructions.

This difference in syntactic behaviour is what motivates linguists such as Chomsky (1981) or Mulder $\&$ den Dikken (1992) to exclude pretty TOUGH-constructions from the TOUGH class. We choose not to do the same thing because, according to us and as we will show later, the behaviour they exhibit is due to a deepstructure difference in the syntactic status of the clausal complement. In our opinion, what defines TOUGHconstructions is their semantic characteristics (the idea of evaluation for example) combined with the apparent puzzle of the position of the theme argument and the problems it involves relative to the case theory. These properties are common to both easy and pretty TOUGH-constructions, justifying their belonging to the TOUGH class.

We can also note that easy TOUGH-constructions and pretty TOUGH-constructions behave differently with regards to the clausal complement: it may be left unexpressed in pretty TOUGH-constructions without changing the entailments, but not in easy TOUGH-constructions:

(46) *Dinosaurs were easy

(47) Trolls ain't pretty

An utterance such as (44) Trolls ain't pretty to look at entails (47), but (42) Dinosaurs were easy to get along with does not entail (46). This seems to indicate that the adjective does not modify the same element in the two constructions. In pretty TOUGH-constructions, it modifies the internal argument directly and the infinitival clause seems to specify some parameter of the meaning of the adjective. In easy TOUGHconstructions, the adjective modifies the internal argument through the process expressed by the infinitival verb.

These differences can be accounted for in terms of a semantic rule that Jones (1983) calls "Property Fusion". It combines the properties expressed by the adjective and those expressed by the infinitival clause to form a

\footnotetext{
${ }^{5}$ When the verb is finite, the inflexion has a nominative case to assign. Because of the case hierarchy, nominative case has to be the first to be assigned. Therefore, there needs to be an argument positioned in the specifier of the inflexion projection. If there is nothing, the derivation fails.

In languages such as Italian, the subject position may remain empty:
}

(a) Sono arrivata

be-prest. arrive-part.-fem.

$\rightarrow \mathrm{I}$ have arrived

At first glance, it would seem that the requirement for nominative case to be assigned is not met here. However, the usual analysis given for utterances like (a) is that the specifier of IP actually contains the null pronoun pro which gets the nominative case available in I:

(c) $\left[\right.$ II $_{\text {nom }}$ I sono arrivata $]$

It is interesting to note that an overt subject can be used in such sentences, but that in this case, it is focalised:

(d) Io sono arrivata me be-prest. arrive-part.fem $\rightarrow \underline{\mathbf{I}}$ have arrived (not John) 
single property. (42) Dinosaurs were easy to get along with can be paraphrased as "in the event of $\mathrm{x}$ getting along with dinosaurs, the getting along is easy". This is impossible with pretty TOUGH-constructions. The property they express is an individual-level property, not a stage-level property, that is to say a defining property and not a transitory property, indexed to a specific event. At the noun phrase level, easy-adjectives are used to modify nouns denoting an activity. They do not easily modify nouns referring to physical entities $^{6}$. Pretty-adjectives, on the contrary, modify nouns denoting physical entities, not activities or states.

Larson (1999) also provides a way of accounting for the differences between pretty and easy TOUGHconstructions. It is illustrated by the difference in the scope of the adjective beautiful in sentences such as Olga is a beautiful dancer. Olga can be both beautiful and a (possibly poor) dancer, or she can be plain but dance beautifully. According to Larson, this is due to the fact that the head noun dancer can be decomposed into two variables : an event "e" (in the Davidsonian sense (Davidson (1967[1980] ) and a participant "x" :

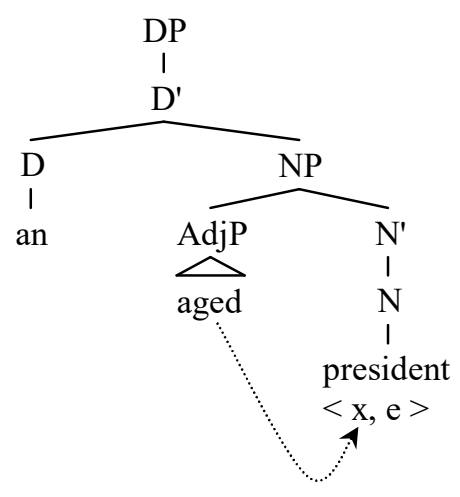

Figure 1

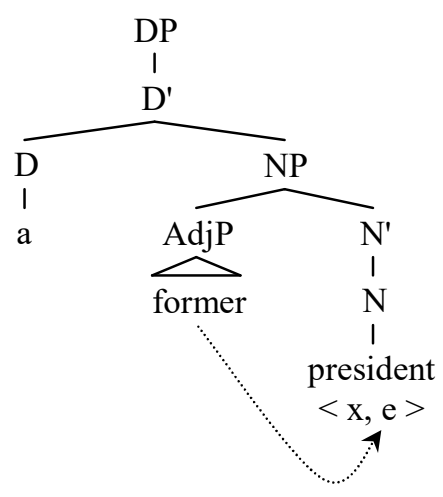

Figure 2

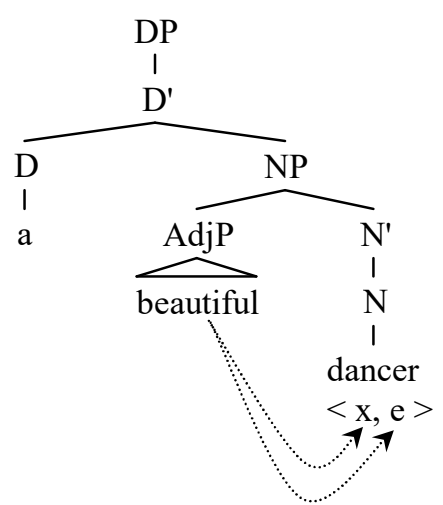

Figure 3

The above trees illustrate the three possibilities as regards the scope of the adjective. In Figure 1, the adjective aged only modifies the participant $\mathrm{x}$, while it modifies only the event $\mathrm{e}$ in Figure 2. In Figure 3, the adjective can modify both the event and the participant, yielding the ambiguity explained above.

The scope of the adjective in pretty TOUGH-constructions such as (44) Trolls ain't pretty to look at is the same as that of aged in Figure 1: it modifies the participant, the subject trolls. In easy TOUGH-constructions such as (42) Dinosaurs were easy to get along with, the adjective modifies both the participant and the event, as represented in Figure 3.

In some cases, it is not possible to erase the infinitival clause, not because it yields an ungrammatical sentence, but because the interpretation of the sentence changes. For the deletion to be possible, the semantics of the grammatical subject needs to be in keeping with the properties expressed by the adjective.

In an example such as the chair is comfortable to sit on, the deletion of the infinitival clause is unproblematic: the chair is comfortable. The entailments are the same, since a chair that is comfortable to sit on is comfortable. The notion COMFORTABLE is naturally associated with nouns referring to clothes or pieces

\footnotetext{
${ }^{6}$ It is possible to find examples such as this woman is easy. However, easy here modifies an event rather than the entity this woman: this woman is easy to seduce.
} 
of furniture such as chairs or sofas. Thus, in an utterance such as (48) below, we would automatically recreate a context in which what is comfortable is a leather jacket, or the fabric covering a car seat:

(48) Leather is perhaps most comfortable.

The real context, however, is the following:

\begin{abstract}
A wide variety of leashes are available from pet shops. Leather is perhaps most comfortable to hold for any length of time, although colourful nylon leashes have become very popular during recent years.
\end{abstract}

BNC CJE

What is comfortable here is a dog leash, and it is absolutely necessary to specify in what circumstances leather leashes are comfortable: when we hold them, not when we sit on them or wear them. Therefore, it is almost impossible to erase the infinitival clause in this utterance.

The same problem occurs with the adjective cheap. This notion is associated with a financial transaction, and therefore with a process like "buy". Reading the utterance this skeleton of a horse will be cheap $^{7}$, we would understand that buying this skeleton of a horse will not be expensive. However, the context is as follows:

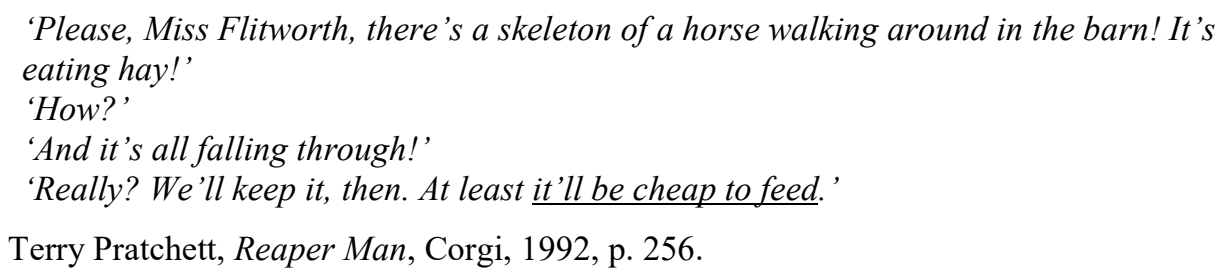

This shows that the interpretation we have imagined is not correct. What is cheap is not the skeleton itself, but the feeding of the skeleton. Such a horse that is only made of bones without flesh or entrails but can walk around and eat would probably be expensive to buy.

\title{
4. Syntactic analysis of TOUGH-constructions
}

We will now present a syntactic analysis that tries to take into account the semantic and syntactic properties of TOUGH-constructions that we described above.

The Government and Binding theory provides a way to distinguish between complements and adjuncts: in syntactic trees, complements are sisters to the lexical level while adjuncts are sisters and daughters to $X^{\prime}$ levels:

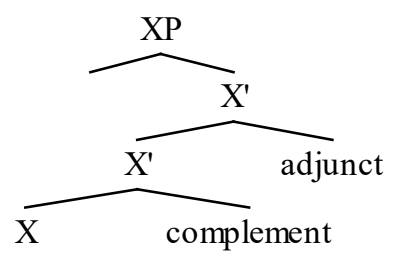

\footnotetext{
${ }^{7}$ The horse in question being Death's horse, an actual skeleton. This sentence is not of the kind You whining coward of a vampire.
} 
One basic property of complements is that they are obligatory while adjuncts are not. The situation, however, is not that simple, since some constituents one would consider to be complements on semantics grounds are optional, while in some cases, adjuncts are obligatory:

(49) Mary hit the ball

\begin{tabular}{|c|c|}
\hline \multicolumn{2}{|c|}{ HIT } \\
\hline Agent & Theme \\
\hline $\mathrm{S}$ & $\mathrm{O}$ \\
\hline Mary & the ball \\
\hline
\end{tabular}

(50) Mary ate (her steak)

\begin{tabular}{|c|c|}
\hline \multicolumn{2}{|c|}{ EAT } \\
\hline Agent & Patient \\
\hline $\mathrm{S}$ & $(\mathrm{O})$ \\
\hline Mary & her steak \\
\hline
\end{tabular}

As these thematic grids show, the external argument the ball is compulsory in an example such as (49). Indeed, *Mary hit is not acceptable. In (50), the argument her steak is optional: Mary ate is perfectly acceptable. However, both internal arguments would be analysed as complements, i.e. as sisters to the head In (51), the prepositional phrase on the beach is optional. To the beach is compulsory in (52) however, as (53) shows:

(51) Mary ate (on the beach)

(52) Mary went to the beach

(53) * Mary went

In both cases, the prepositional phrase would be analysed as an adjunct, i.e. as sister and daughter to an X' level.

These properties are relevant in the study of TOUGH-constructions. As we saw above, the clausal complement can be erased in pretty TOUGH-constructions: (47) Trolls ain't pretty is perfectly acceptable. The semantic content is not exactly the same however, since the event in which the property pretty is predicated of the subject is not mentioned. This is can be properly rendered by giving adjunct status to the infinitival clause:

Trolls ain't pretty to look at

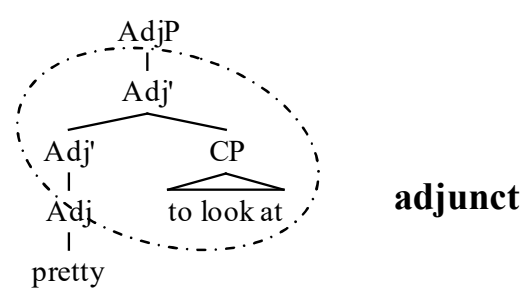

This clause cannot be erased in easy TOUGH-constructions. This would be best illustrated in the following tree, where the CP has complement status instead of adjunct status:

Dinosaurs were easy to get along with

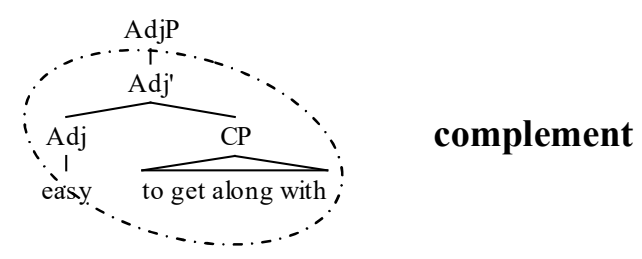


To include in a syntactic analysis the notion of evaluation that is central to TOUGH-constructions, we need a functional projection. We will call it Eval(uation)P. It is headed by the adverb when it is present and needs to be of the "shell" type, that is to say containing a "light" head, similarly to the $v$ P-Shell:

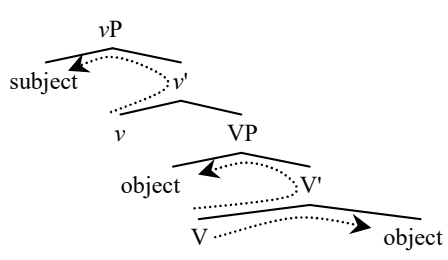

The $v$ P-Shell is used to account for double-object verbs such as give, which are analysed as having a causative structure : GIVE = cause to go/get. The higher verb is a "light" causative verb noted $v$. It assigns a thematic role to argument in [Spe- $v \mathrm{P}]$. The lower verb, $\mathrm{V}$, assigns a role to the objects in [Spe-VP] and in the position sister to V. A sentence such as Mary gave John a book would have the following structure:
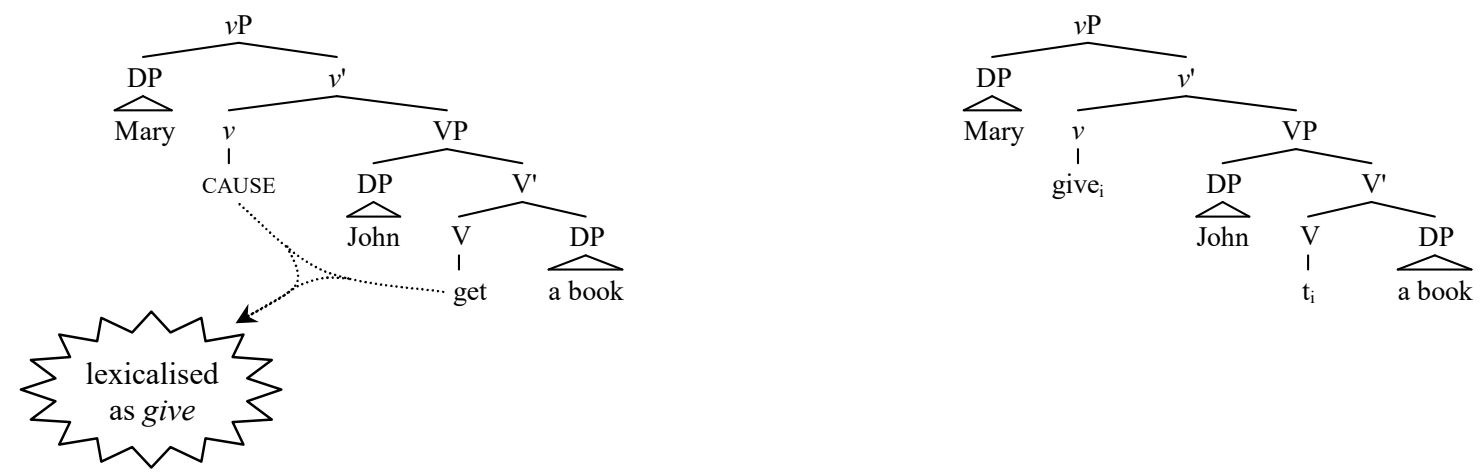

In our derivation, we choose to use this kind of structure to account for the close relationship that exists between the adverb on the one hand and the adjective and the infinitival clause on the other hand. The structure of the "evalP-Shell" would be the following :

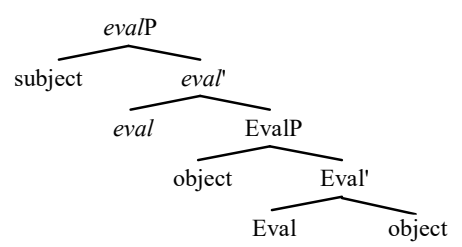

In this analysis, the adverb is positioned in eval. This is the head which gives its evaluative interpretation to the whole structure. It would be difficult to justify the presence of a projection whose head remained empty, therefore eval needs to be filled at all times, by an adverb with or without phonetic content.

The grammatical subject is in [Spe-evalP] and the adjective is complement of Eval. At the beginning of the derivation, the infinitival clause fills the [Spe-EvalP] position, which is an object position in the $v \mathrm{P}-$ Shell. This accounts for the fact that when the adjective is descriptive, both the adverb and the infinitival clause are compulsory: the adverb selects the clause ${ }^{8}$ and therefore needs to be in the same projection.

As illustrated below, the adjective rises to Eval in order to give the evaluative meaning that all TOUGH-constructions have in common:

\footnotetext{
${ }^{8}$ Faraci 1974.
} 
Trolls ain't pretty to look at.

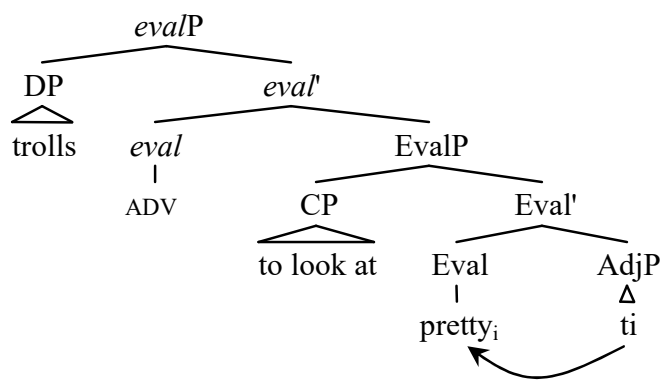

Dinosaurs were (too) easy to get along with.

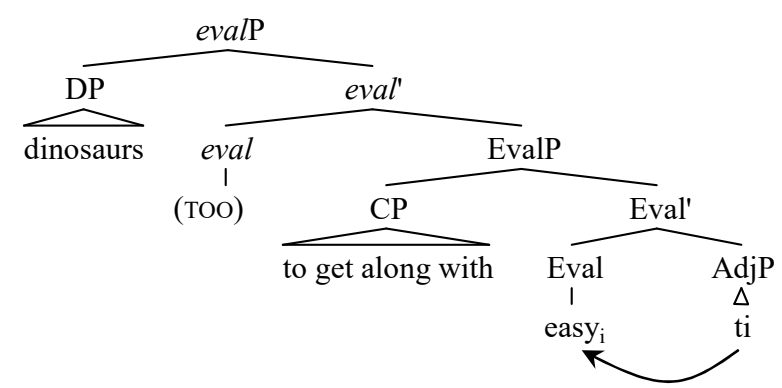

Another reason to this movement is that since a property is predicated of the subject, this subject needs to be situated in the same projection (here, the Shell projection) as the adjective expressing the property.

However, this movement should not occur in examples containing a descriptive adjective. In those cases, it is the adverb which gives the evaluative meaning to the sentence. If the Eval position is filled by the raised adjective, thus providing the evaluative meaning, the presence of the adverb becomes superfluous, which it is not. Therefore, we need to elaborate a particular derivation for TOUGH-constructions containing a descriptive adjective:

The outer walls are too sheer to climb.

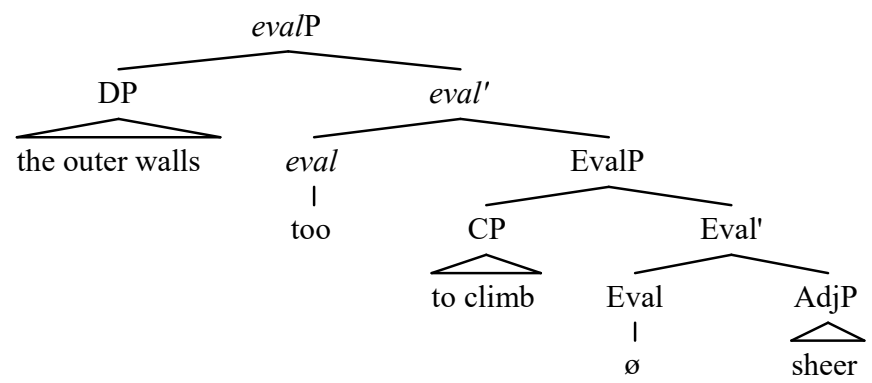

Here, the adjective sheer does not rise to Eval, which remains empty.

As can be seen in the above trees, the position of the infinitival clause is not what is expected. Moreover, these structures violate the Head Final Filter ${ }^{9}$. According to this principle, a pre-modifier must be head final, that is to say it cannot have a complement. This forbids structures like the following:

(54) $* a_{\mathrm{AP}}$ keen $[\mathrm{pP}$ on jazz] $]$ student

(55) *a [CP which [IP I published in 1991]] book

As we explained above, the specifier of $\mathrm{XP}$ in shell-type projections is an object position. Therefore, the $\mathrm{CP}$ in [Spe-EvalP] in TOUGH-constructions violates the Head Final Filter since it is complement to the adverbial head too:

(56) *dinosaurs were $\left[_{\mathrm{ADJP}}\left[\mathrm{ADvP}\right.\right.$ too ${ }_{[\mathrm{CP}}$ to get along with] easy]

\footnotetext{
${ }^{9}$ Williams 1981, also known as "Surface Recursion Principle" (Emonds 1976).
} 
Trolls ain't pretty to look at.

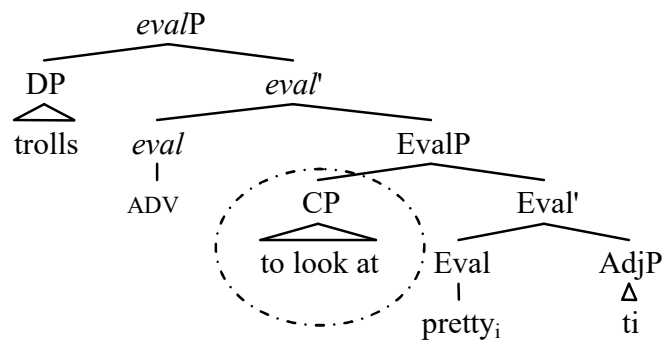

Dinosaurs were (too) easy to get along with.

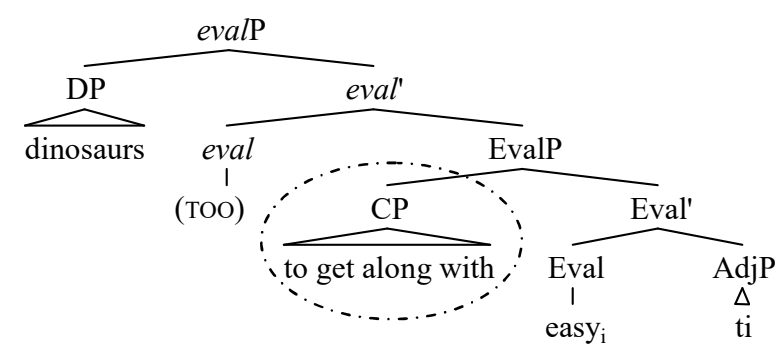

The solution would be that the CP moves from its initial [Spe-EvalP] position to the position of adjunct (in pretty TOUGH-constructions) or complement (in easy TOUGH-constructions) of the adjective (before its movement), which would yield the correct word order:

(57) *dinosaurs were $\left[\mathrm{ADJP}\left[\mathrm{ADvP}\right.\right.$ too $\left.\mathrm{t}_{\mathrm{i}}\right]$ easy $\left.[\mathrm{CP} \text { to get along with }]_{\mathrm{i}}\right]$

Trolls ain't pretty to look at ${ }^{10}$.

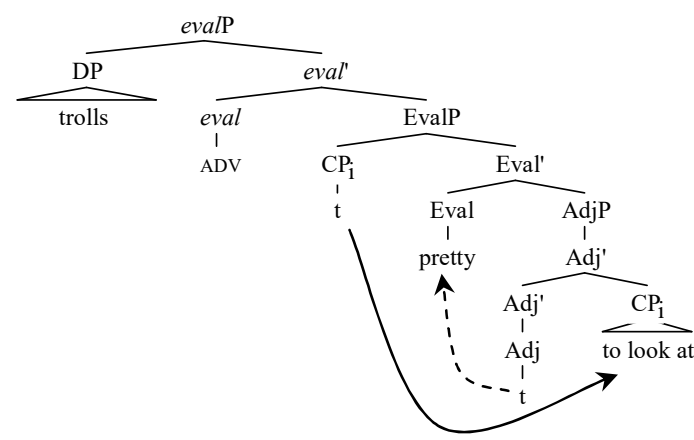

Dinosaurs were (too) easy to get along with.

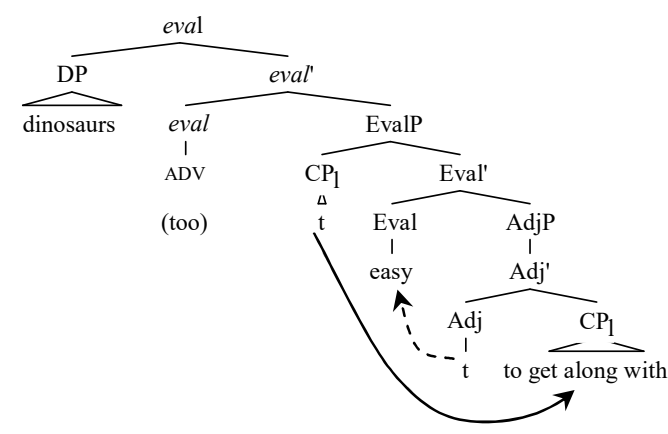

The same movement occurs in examples containing a descriptive adjective :

The outer walls are too sheer to climb.

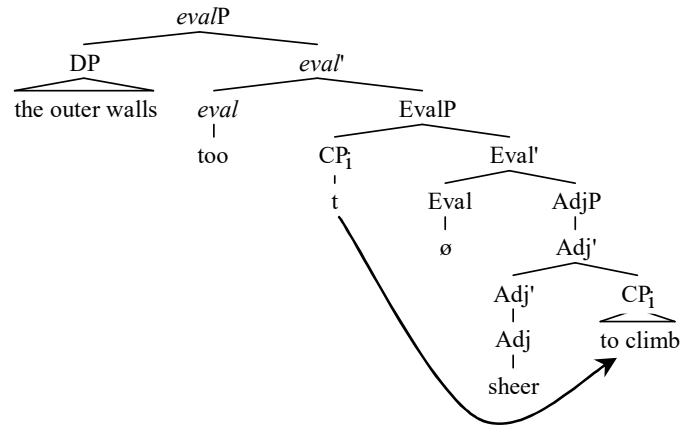

As we have seen above, the grammatical subject in TOUGH-constructions is a theme. Usually, this semantic role is assigned by the verb to its object, not to its subject. Therefore, suppose the grammatical

\footnotetext{
${ }^{10}$ The label ADV is used to refer to the adverb without phonetic realisation. Which adverb it actually is is difficult to determine. One can only say that it cannot be TOO, since the meaning of the sentence would be different from what it is :
}

(a) Trolls ain't too pretty to look at $\quad \neq \quad$ Trolls ain't pretty to look at. 
subject originates in object position, as suggested by Rosenbaum and Postal ${ }^{11}$. The correct TOUGH structure should then be the following:

Dinosaurs were easy to get along with

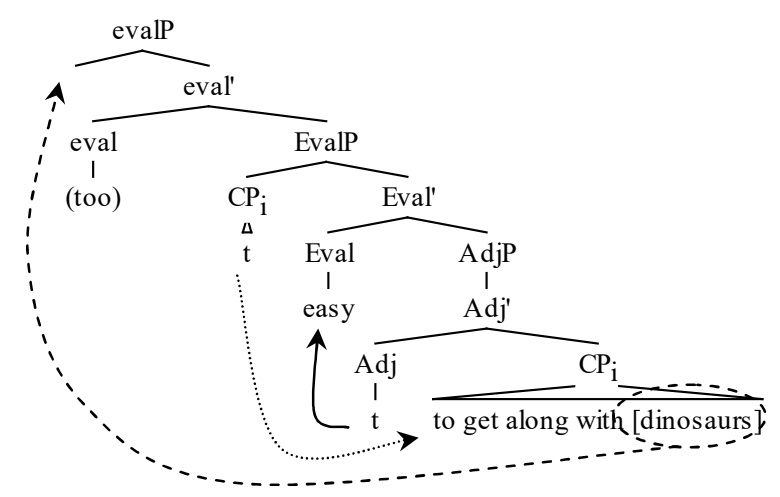

The DP dinosaurs originates in the complement position of the lower verb from which it gets its role and accusative case ${ }^{12}$. It then rises to [Spe-EvalP] and then to the [Spe-IP] subject position:

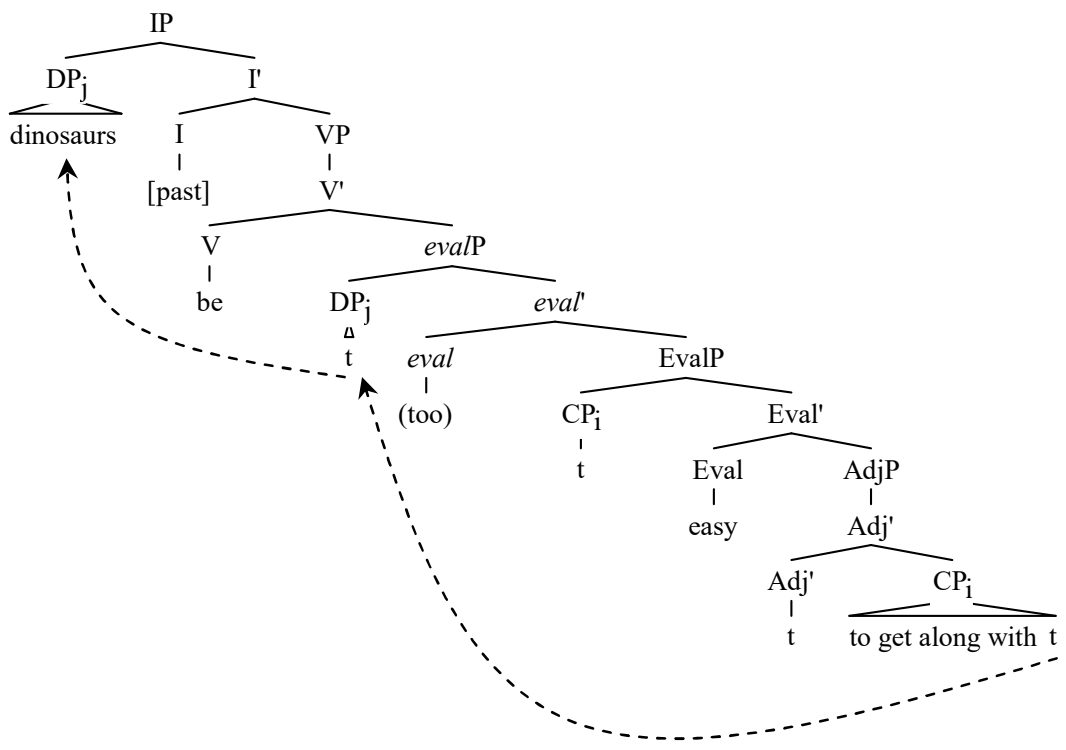

This is the point where the case problem arises. When the DP subject rises to [Spe-IP], it gets nominative case from the inflection. Therefore, it has two cases, accusative and nominative, which is forbidden by the Case Filter.

The solution to this problem can be found in examples like the following:

(58) ready-to-wear

$$
\text { Nanni (1980) }
$$

(59) an impossible-to-answer question

George Ehrenhaft, John Steinbeck's The Grapes of Wrath, Barron's Educational Series, 1985.

(60) an easy-to-take laxative

Nanni (1980)

\footnotetext{
${ }^{11}$ We are aware of the fact that this analysis was previously declared problematic. We will use a variant of it, solving the case problem it involved.

${ }^{12}$ Note that in this example, since the verb is indirect transitive, it is the preposition with which assigns (dative) case to the DP dinosaurs.
} 
Such examples should be ungrammatical since they seem to violate the Head Final Filter: the infinitive clause cannot be erased:

(61) *an easy laxative

This surprising grammaticality, in addition to the dashes linking the adjective and the elements of the infinitival clause, suggests that these elements form a group that has been lexicalised to some degree and now forms a single unit, just like Chomsky's (1981) complex adjective. Indeed, it is not possible to reintroduce the agent with a for-PP, as is possible with classical TOUGH-constructions:

(62) *ready-for-me-to-wear

(63) a dialect too ancient for me to follow

Marion Zimmer Bradley, Heritage and Exile, 'The Heritage of Hastur', Fantasy Daw, 1975, p. 331

We might assume that this lexicalization also occurs in TOUGH-constructions, but after the stage where the agent can be re-introduced, which would make it possible for it to be present.

Our proposal is that a process similar to lexicalization is the reason why a raised object can be found in subject position: communication between the raised theme and its original position would be impossible because the chain they form would be cut.

Chains indeed enable cases to be transmitted from one position to another. This is said to occur in the case of some unaccusative verbs, such as arrive.

(64) a man arrived

(65) There arrived a man

The deep structure of a sentence containing the verb arrive is the following:

(66) arrived a man

The DP a man is in object position of the verb from which it gets a role. Unaccusative verbs cannot assign accusative case to their internal argument but the DP still needs a case in order to satisfy the Case Filter. Moreover, the requirement in English that all sentences need a subject (EPP) has to be met. Two solutions are possible. The first one is illustrated in (64). Here, the object a man rises to the position of subject (specifier of IP) where it gets nominative case. The second solution, (65), does not involve movement of the object but instead the insertion in subject position of the expletive pronoun there which transmits its case via the chain it forms with the object DP.

We would then have the following structure for TOUGH-constructions:

Dinosaurs were [(too) easy to get along with] 


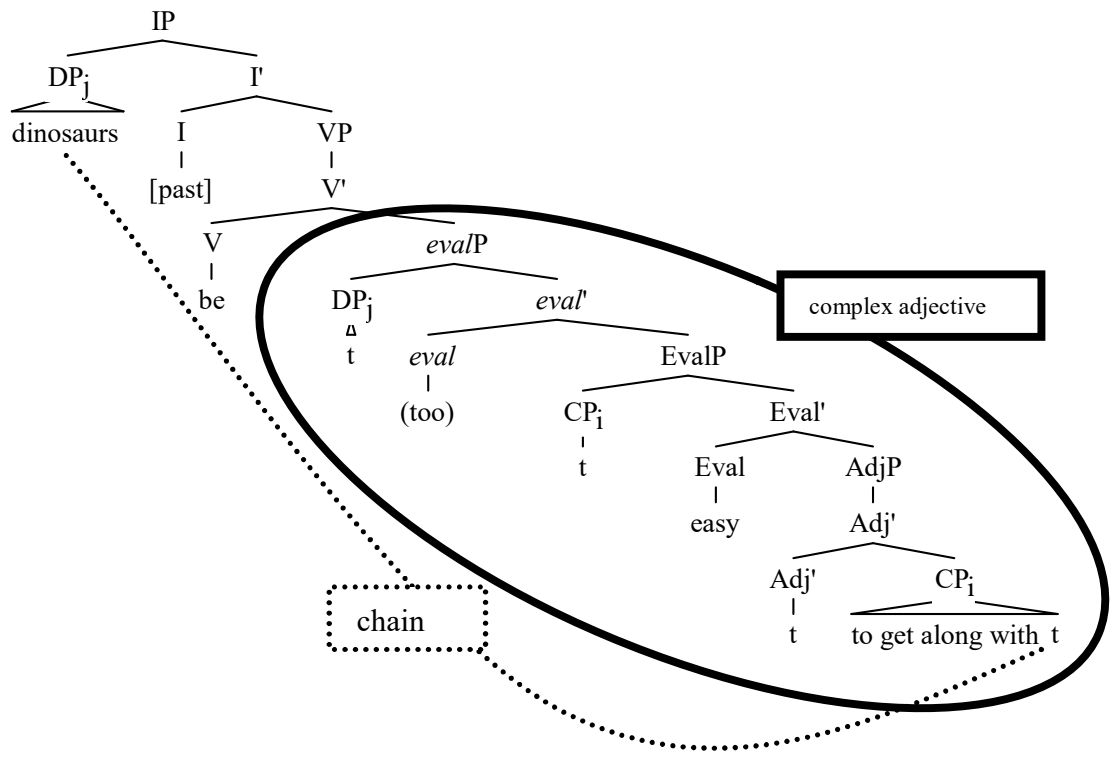

The trace left by the DP the dinosaurs being inside the complex adjective, the chain between the deep structure position and the surface structure position is cut, which prevents the case from being transmitted. The theme subject therefore needs another case, which it gets from the head I.

TOUGH-constructions are very interesting to study because they pose a serious problem to the theory of Government and Binding. What could be considered as the "intuitive" analysis, that is the analysis according to which the internal argument rises to subject position, is rendered impossible by the Case Filter: arguments can have only one case. Our proposal adapts Rosenbaum and Postal's raising analysis but combines it with Chomsky's complex adjective analysis. This enables us to provide a solution to the case problem: after the internal argument rises to subject position, a complex adjective is formed via a process similar to lexicalization, which has the effect of cutting the communication between the raised argument and its trace. The result is that the object case, accusative, cannot be transmitted to the already case-marked subject, thus avoiding violation of the Case Filter.

Our proposal also takes into account the semantic and "basic" syntactic properties of TOUGH-constructions: the evaluative interpretation and the different behaviour as regards expletives and deletion of the infinitival complement. The use of a functional "shell" projection has enabled us to account for the evaluativeness of TOUGH-constructions, and the different syntactic status of the complement clause depending on the type of adjective used explains the differences in syntactic behaviour.

\section{BIBLIOGRAPHY}

Chomsky N., Lectures on Government and Binding, the Pisa Lectures, Dordrecht, Foris, 1981. 
Dalrymple M., Holloway King T., « Missing-Object Constructions: Lexical and Constructional Variation », in Proceedings of the LFG00 Conference, University of California, Berkeley, Miriam Butt and Tracy Holloway King (Eds. ), 2000.

http://csli-publications.stanford.edu/LFG/5/lfg00dalrymple-king.pdf

Davidson, D., « The Logical Form of Action Sentences », in Essays on Actions and Events, Oxford, O.U.P, 1967 [1980].

Emonds J., A Transformational Approach to English Syntax, Academic Press, New York, 1976.

Faraci R., Aspects of the Grammar of Infinitives and for-Phrases, Doctoral Dissertation, MIT, 1974.

Hicks, G., «'So Easy to Look at, so Hard to Define' : Tough Constructions and their Derivation », Ms., University of York, 2004.

http://www-users.york.ac.uk/ gdh103/

Jones M., « Getting 'Tough' with Wh-Movement », Journal of Linguistics, 19, 1983, p. 129-159.

Khalifa, J-C., «Tough-Movement or Tough-Construction ? (or Too Tough to Tell ?) », Journées ALAES, Université Sorbonne, Paris IV, 2007.

http://djamet42.free.fr/ALAES/Concours/2007/adjectifs/Khalifa_adjectifs.pdf

Larson R. K., «Semantics of Adjectival Modification », Lectures at the LOT Winter School, Amsterdam, 1999.

Mulder R., den Dikken M., « Tough Parasitic Gaps », in Proceedings of NELS 22, Amherst: GLSA, 1992.

Munn, A., «A Minimalist Account of Reconstruction Asymmetries », in Proceedings of NELS 24, Merce Gonzalez (Ed.), 1994, p. 397-410.

http://citeseerx.ist.psu.edu/viewdoc/download?doi=10.1.1.37.2317\&rep=rep1\&type=pdf

Nanni, D., «On the Surface Syntax of Constructions with Easy-Type Adjectives », Language, T 56, n³, 1980, p. 568-603.

Postal P., Cross-over Phenomena, New York, Holt, Rinehart and Winston, 1971.

Rosenbaum P., The Grammar of English Predicate Complement Constructions, Cambridge, Mass. : MIT Press, 1967.

Williams E., « Argument Structure and Morphology », The Linguistic Review, 1, 1981, p. 81-114. 